\title{
Pathogenesis and management of alcoholic liver cirrhosis: a review
}

\author{
This article was published in the following Dove Press journal: \\ Hepatic Medicine: Evidence and Research \\ 23 December 2010 \\ Number of times this article has been viewed
}

\author{
Yi-Wen Huang ${ }^{1,2}$ \\ Sien-Sing Yang ${ }^{* 1,3}$ \\ Jia-Horng Kao*2,4,5 \\ 'Liver Center, Cathay General \\ Hospital Medical Center, Taipei, \\ Taiwan; ${ }^{2}$ Division of Gastroenterology, \\ Department of Internal Medicine, \\ National Taiwan University College \\ of Medicine and National Taiwan \\ University Hospital, Taipei, Taiwan; \\ ${ }^{3}$ Faculty of Medicine, Fu-Jen Catholic \\ University College of Medicine, Taipei, \\ Taiwan; ${ }^{4}$ Graduate Institute of Clinical \\ Medicine, National Taiwan University \\ College of Medicine, Taipei, Taiwan; \\ ${ }^{5}$ Hepatitis Research Center, National \\ Taiwan University Hospital, Taipei, \\ Taiwan \\ "Sien-Sing Yang and Jia-Horng Kao \\ contributed equally to the work
}

\begin{abstract}
Little is known about how alcohol causes liver disease and cirrhosis. The strongest evidence of the causality between alcohol and liver disease stems from epidemiological observations. Factors contributing to alcohol-induced fibrosis and cirrhosis include cytokines, oxidative stress, and toxic metabolites of ethanol. Patients with alcoholic cirrhosis generally have complications at diagnosis, and cirrhotic complications should be actively assessed because they are closely associated with subsequent morbidity as well as mortality. Abstinence is strictly required to prevent disease progression and is critical for eventual liver transplantation. In addition, nutritional therapy remains the mainstay of managing alcoholic cirrhosis.
\end{abstract}

Keywords: alcohol, cirrhosis, complication, treatment

\section{Introduction}

Alcoholism is a global health problem. Liver metabolizes most of the ingested alcohol. Among individuals who consume more than 70 drinks $(1$ drink $=$ one $12 \mathrm{oz}$. beer at $4 \%$ alcohol or one $1.5 \mathrm{oz}$ glass of wine at $11 \%$ alcohol) per week for over 20 years, $19 \%$ developed alcoholic liver disease and 7\% developed cirrhosis. ${ }^{1}$ Thresholds of ethanol consumption per week for the development of alcoholic liver disease were 7 to 13 drinks for women and 14 to 27 drinks for men. ${ }^{1}$ Alcoholic liver disease can be divided on histology into steatosis, hepatitis, hepatitis superimposed on early cirrhosis, and cirrhosis. ${ }^{2}$ When symptoms occur in individuals with alcohol abuse, many of them already have progressed to cirrhosis. The risk of cirrhosis correlates strongly with past and current alcohol drinking, ${ }^{3}$ and many patients with alcoholic cirrhosis have complications at diagnosis.

\section{Pathogenesis of alcoholic fibrosis and cirrhosis}

It is incompletely understood how alcohol causes liver disease and cirrhosis. The strongest evidence of the causality is deduced from epidemiological studies, showing a strong correlation between ethanol consumption and alcoholic liver disease as well as cirrhosis. ${ }^{1,3}$ Prohibition of alcohol drinking can result in a marked reduction of liver-related deaths in patients with alcoholic liver disease. ${ }^{4}$ Data from genetic polymorphisms in alcohol metabolism further support this association. Ethanol is metabolized in hepatocyte cytosol by alcohol dehydrogenase (ADH) to acetaldehyde, which is subsequently metabolized in the mitochondria by acetaldehyde dehydrogenase (ALDH) to acetate. Polymorphisms of $A D H$ and $A L D H$ genes correlate with occurrence of alcoholic liver disease in Japanese ${ }^{5,6}$ and with alcoholic cirrhosis in Taiwanese. ${ }^{7,8}$ 
Most patients with alcoholic steatosis progress to steatohepatitis and subsequent fibrosis or even cirrhosis. Reactive oxygen species (ROS) are produced in hepatocytes through induction of cytochrome P450 2E1. ${ }^{9,10}$ Oxidative stress, hepatocytes injury by ROS, is a major determinant in alcoholic liver injury and fibrosis. ${ }^{11,12}$ Production of ROS results in reduced antioxidant glutathione/glutathione disulfide ratio. ${ }^{13,14}$ On liver histology, hepatocyte injury is most significant in pericentral regions, where pericentral fibrosis occurs. The latter is also known as sclerosing hyaline necrosis or perivenular fibrosis. In addition, Mallory bodies are an important marker of alcoholic liver injury, ${ }^{15}$ but they do not have a pathogenic role in the liver damage.

Hepatic stellate cells, the major source of extracellular matrix in hepatic fibrosis, are also stimulated by ROS. Activation of stellate cells is observed during liver injury, resulting in their proliferation and resulting fibrogenesis. ${ }^{16}$ Studies in experimental alcoholic injury and human alcoholic fibrosis support the central pathway of stellate cell activation in their pathogenesis. ${ }^{17,18}$ Initiation of the activation results mostly from paracrine stimulation by Kupffer cells, hepatocytes, sinusoidal endothelium, and platelets. Recent identification of the receptor for bacterial lipopolysaccharide, Toll-like receptor 4 (TLR4), in stellate cells and Kupffer cells reveals its role in fibrogenesis. ${ }^{19}$ TLR4 enhances TGF-beta-1 signaling, which is the major fibrogenic cytokine in the liver. ${ }^{20}$

Other mediators may also play a role in alcoholic fibrogenesis. Acetaldehyde, but not alcohol itself, has adjunctive fibrogenic activity in cultured stellate cells. ${ }^{21}$ In experimental rodents fed with alcohol, there is an increased in lipid aldehydes, which are unstable intermediates during interaction of ROS and cellular proteins. ${ }^{22,23}$ In addition, several reports have addressed the involvement of pro-inflammatory cytokines such as tumor necrosis factor and interleukin-6 in hemodynamic changes of patients with cirrhosis. ${ }^{24,25}$

\section{Clinical manifestations and diagnosis of alcoholic cirrhosis}

Clinical presentations of alcoholic cirrhosis vary from asymptomatic to hepatic decompensation with complications. ${ }^{26}$ Specific diagnosis for alcoholic cirrhosis is summarized in Table 1. Detail history taking is mandatory for diagnosis. Alcoholic cirrhosis is diagnosed in many individuals with alcohol abuse when they have symptoms. These patients may have malnutrition, parotid enlargement, vascular spiders, palmar erythema, hepatosplenomegaly, portal hypertension, fluid and electrolyte redistribution, feminization, neuropathy, and encephalopathy. ${ }^{27}$ Laboratory findings show
Table I Specific diagnosis for alcoholic cirrhosis

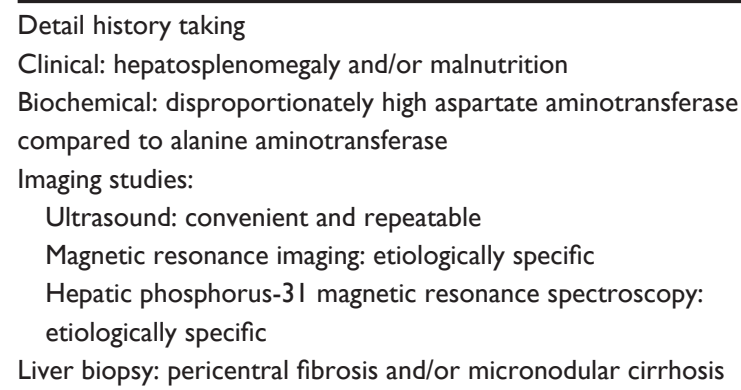

disproportionate elevation of serum aspartate transaminase compared to alanine transaminase, hypoalbuminemia, hyperbilirubinemia, anemia, leukopenia, thrombocytopenia, prolonged prothrombin time, and partial thromboplastin time. Reduced platelet count and function reflect hypersplenism.

Ultrasound, computed tomography scan, and magnetic resonance imaging (MRI) are well-known imaging tools to diagnose cirrhosis or concomitant neoplastic diseases. Typical imaging studies of alcoholic cirrhosis show hepatomegaly, bluntness of liver edge, irregular liver surface, and coarse liver texture..$^{28,29}$ MRI may also be used to differentiate alcoholic cirrhosis from cirrhosis of viral hepatitis by the detection of caudate lobe enlargement and the presence of the right posterior hepatic notch. ${ }^{29}$ Patients with alcoholic cirrhosis with lower phosphodiesterase to adenosine triphosphate ratios may be differentiated from cirrhosis of other etiologies by using hepatic phosphorus-31 magnetic resonance spectroscopy (HP31 MRS)..$^{30}$ In addition, HP31 MRS has the ability to calculate hepatic phospholipid metabolism, which can be used to distinguish alcoholic cirrhosis from noncirrhosis. ${ }^{31}$

On liver histology, cirrhosis is characterized by hepatic architecture distortion and the formation of regenerative nodules. For patients with advanced alcoholic cirrhosis, the diagnosis is usually made on the basis of clinical, biochemical, imaging, and hemodynamic findings. However, for those without typical manifestations, a liver biopsy is required to establish the diagnosis. ${ }^{2,32,33}$ Liver biopsy is also beneficial to exclude coexisting liver diseases and to evaluate the severity of concurrent alcoholic hepatitis. ${ }^{34}$ The reversibility of alcoholic fibrosis may be greater than other causes of fibrosis if there is a prominent inflammatory component due to recent ethanol abuse. Histological factors predicting the irreversibility and advanced cirrhosis include micronodular cirrhosis and thickened septae. ${ }^{35,36}$ Both alcoholic hepatitis and fibrosis first appear in the pericentral zone, and progress to panlobular fibrosis in continuous drinkers. ${ }^{37}$ Therefore, the pericentral fibrosis can serve as an early marker of progression to cirrhosis. ${ }^{32,38}$ 
Transient elastography (TE) has been introduced as a noninvasive assessment of hepatic fibrosis in patients with chronic viral hepatitis. ${ }^{39}$ However, TE may not be reliable in patients with concurrent hepatitis and cirrhosis. ${ }^{40,41}$ The clinical application of TE in alcoholic cirrhosis, especially in those with concurrent alcoholic hepatitis, thus requires further examinations.

\section{Complications and prognosis of alcoholic cirrhosis}

Patients with alcoholic cirrhosis are vulnerable to various complications which threaten their life expectancy (Figure 1). Studies have shown the high prevalence of complications at the time of initial diagnosis of alcoholic cirrhosis. ${ }^{42,43}$ Complications include occurrence of ascites, varices with their related hemorrhage, hepatic encephalopathy, spontaneous bacterial peritonitis, hepatorenal syndrome, hepatopulmonary syndrome, and hepatocellular carcinoma. These complications lead to high mortality in patients with alcoholic cirrhosis. In contrast, prevention and treatment of complications may lead to the prolonged survival.

Patients are considered to have decompensated liver disease when complications of cirrhosis develop. Factors predicting poor prognosis include continued alcohol use and the presence of hepatic inflammation. For example, patients with decompensated alcoholic cirrhosis who continue drinking have a 5-year transplant-free survival of 30\% versus $60 \%$ for those who quit drinking. ${ }^{26,44-46}$

\section{Ascites}

Portal hypertension leads to development of ascites, ie, fluid retention in the peritoneal cavity. Ascites is the most common complication of cirrhosis. The mechanisms of sodium and water retention include activation of the renin-angiotensin-aldosterone system and sympathetic nervous system. The impairment in urinary sodium excretion in cirrhosis correlates with liver function. ${ }^{47}$ In addition, nonosmotic hypersecretion of antidiuretic hormone is observed. Ascites develop in 58\% of patients within 10 years of compensated cirrhosis. ${ }^{48}$ In a population-based cohort study on the clinical course of alcoholic cirrhosis, the presence and type of 3 complications (ie, ascites, variceal hemorrhage, and encephalopathy) could predict mortality. ${ }^{42}$ However, this study may have underestimated the rate of complications, due to the detection of ascites mainly by physical findings and nonassessment of varices per se. ${ }^{43}$ Ultrasound is useful to detect minimal amount of ascites, as well as the presence of portal hypertension. ${ }^{28,49}$ Early detection of ascites in patients with cirrhosis is important to predict long-term outcomes. ${ }^{50}$ Complications of cirrhosis should be assessed actively to allow early management of complications and reduce subsequent mortality.

\section{Varices and related hemorrhage}

The detection of varices in patients with cirrhosis is important. ${ }^{50}$ Endoscopy is well known to detect varices in patients with cirrhosis. The newly developed narrow band imaging system may assist the detection of varices. ${ }^{51}$ The occurrence of varices per se has been reported to predict mortality in patients with alcoholic cirrhosis. ${ }^{52}$ Variceal hemorrhage occurs in $25 \%$ to $40 \%$ of patients with cirrhosis, ${ }^{53}$ and it is a devastating complication, with 1 -year mortality of $20 \% .^{42}$

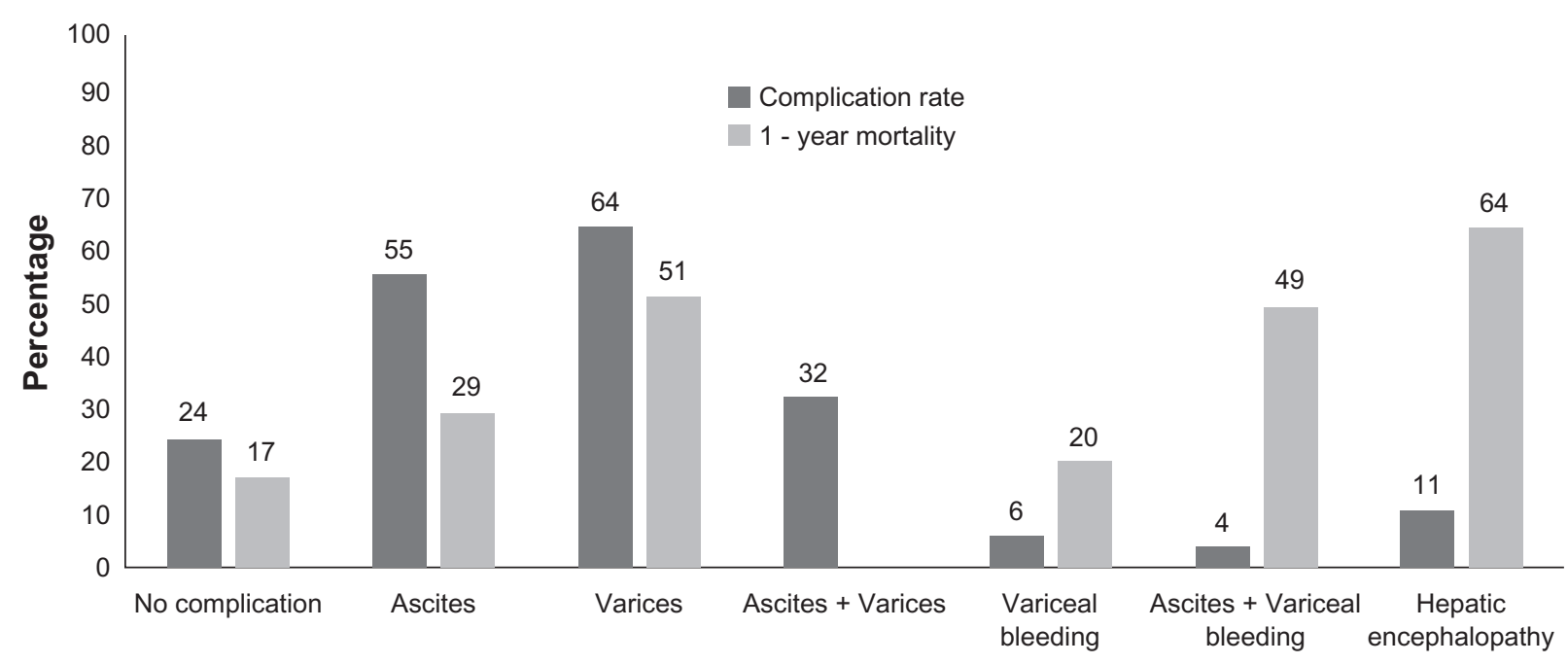

Figure I Rates of complications at diagnosis of alcoholic cirrhosis and I-year mortality following complications. From data of Jepsen et al, ${ }^{42} \mathrm{Huang}$ et al, ${ }^{43}$ and Lin et al..$^{52}$ 


\section{Hepatic encephalopathy}

Hepatic encephalopathy is a potentially reversible alteration of brain function in patients with liver decompensation. The diagnosis of hepatic encephalopathy should be made after exclusion of unrelated neurologic or metabolic abnormalities. The definition of hepatic encephalopathy is difficult in patients with alcoholic liver disease who have initial neurologic manifestations as part of diffuse central and peripheral neuropathy. Patients with alcoholic cirrhosis have delayed nerve conduction and evoked potentials. ${ }^{54,55}$ Neuropsychiatric testing to detect minimal hepatic encephalopathy may be considered for patients with alcoholic liver disease who are at increased risk. A study reported that alcoholic cirrhotic patients with minimal hepatic encephalopathy have driving impairment and should be avoided. ${ }^{56}$

\section{Spontaneous bacterial peritonitis}

Spontaneous bacterial peritonitis (SBP) refers to an ascitic fluid infection without evidence for an intra-abdominal surgically treatable source. SBP mostly occurs in patients with advanced cirrhosis. ${ }^{57}$ Diagnostic criteria for SBP are a positive ascitic fluid bacterial culture and elevated ascitic fluid absolute polymorphonuclear leukocyte (PMN) count ( $\geq 250$ cells $/ \mathrm{mm}^{3}$ ). The latter is adequate to start empirical antibiotic treatment.

\section{Hepatorenal syndrome}

The hepatorenal syndrome (HRS) is an acute renal failure usually found in patients with cirrhosis or severe alcoholic hepatitis. ${ }^{58-60}$ HRS represents the end-stage of a sequence of reductions in renal perfusion with the scenario of deteriorating liver injury. The diagnosis of HRS is made by excluding other causes of renal impairment. The prognosis is poor unless underlying liver disease can be improved or liver transplantation can be performed.

\section{Hepatopulmonary syndrome}

Hepatopulmonary syndrome (HPS) is diagnosed in patients with the triad of liver disease, increased alveolar-arterial gradient while breathing room air, and evidence for intrapulmonary vascular dilatations. ${ }^{61,62}$ Prevalence of HPS ranges from $4 \%$ to $47 \%$. ${ }^{63,64}$ Patients with cirrhosis commonly have mild hypoxemia which may have resulted from ascites or pleural fluid compression to the lung parenchyma. ${ }^{65} \mathrm{HPS}$ should be suspected if severe hypoxemia $\left(\mathrm{PaO}_{2}<60 \mathrm{mmHg}\right)$ is detected in the absence of cardiopulmonary disease. ${ }^{66}$

\section{Hepatocellular carcinoma}

Although advanced fibrosis is known to be a strong risk factor for hepatocellular carcinoma (HCC) development, patients with alcoholic liver disease are not at an increased risk until cirrhosis develops. Patients with small $\mathrm{HCC}(<3 \mathrm{~cm})$ are often asymptomatic. The development of HCC should be suspected in a patient with cirrhosis who has serum alphafetoprotein (AFP) elevation. However, serum AFP level is normal in up to $40 \%$ of small HCCs. ${ }^{67}$ Elevated AFP may be more likely in viral hepatitis-related than in alcoholic liver disease-related HCC. ${ }^{68}$

Patients with alcoholic cirrhosis should undergo surveillance for HCC by using ultrasound and AFP. AFP alone should not be used for the screening purpose. Regenerative nodules, as one of histological features of patients with alcoholic cirrhosis, are commonly detected on ultrasound or other imaging studies. Sometimes it may be difficult to distinguish regenerative nodules from $\mathrm{HCC}$, even by contrast-enhanced imaging modalities. In such cases, liver biopsy to the target lesion should be performed.

\section{Prognosis and predictive models}

The prognosis of liver cirrhosis is influenced by the following factors: etiology, severity, presence of complications, and comorbid illness. Child-Pugh classification based on 5 parameters (ascites, bilirubin, albumin, prothrombin time, and encephalopathy) is useful to predict the overall prognosis, development of complications, and surgical risk. One-year survival rates for patients with Child-Pugh A, B, and C cirrhosis are $100 \%, 80 \%$, and $45 \%$, respectively. ${ }^{69,70}$ Model for End Stage Liver Disease (MELD) using bilirubin, creatinine, INR, and etiology of cirrhosis can also be used to predict outcomes in cirrhosis.

Histologic findings can also predict prognosis in alcoholic cirrhosis, ie, patients with alcoholic hepatitis on cirrhosis had higher mortality. ${ }^{71}$ In addition, patients with alcoholic hepatitis on cirrhosis usually have elevated sum of asymmetric dimethylarginine and its stereoisomer. ${ }^{72}$ To predict disease severity and mortality risk in alcoholic hepatitis, Maddrey's discriminant function, Glasgow alcoholic hepatitis score, and the Lille model are commonly used. ${ }^{73-76}$ Finally, obese patients with alcohol abuse may have higher risk of advanced liver disease. ${ }^{77}$

\section{Prevention and treatment of alcoholic cirrhosis}

Current prevention and treatment of alcoholic cirrhosis are summarized in Table 2. Among these measures, abstinence 
Table 2 Prevention and treatment of alcoholic cirrhosis

Alcohol abstinence

Nutritional support: short- and long-term benefit

Frequent small quantity feeding

Micronutrients and vitamin replacement

High protein and kilocalorie

Liver transplantation

Psychosocial support

Quit smoking

Avoid hepatotoxic agents

Vaccination (hepatitis A, B, pneumococcus, and influenza)

of alcohol drinking is fundamental and still beneficial even in cirrhotic patients to prevent disease progression and is critical for eventual liver transplantation. Patients who stop drinking may reduce or normalize portal pressure, ${ }^{78}$ reduction of ascites, ${ }^{79}$ and improve fibrosis. ${ }^{80,81}$

Serum albumin level has been used as an indicator for nutritional status in patients with cirrhosis ${ }^{82}$ and nutritional therapy is a mainstay of good practice in alcoholic cirrhosis. In order to improve nutritional balance, frequent small quantity feeding with a morning meal and snack at night time are recommended.$^{83}$ Micronutrients and vitamin replacement should also be provided as part of the treatment. ${ }^{83}$ Nutritional deficiencies are common in alcoholism. ${ }^{84}$ However, few data have confirmed that aggressive nutritional supplementation can reverse the catabolism and inflammation of alcoholic liver disease. Nevertheless, short-term survival outcomes are improved in enteral feeding during hospitalization for severely malnourished alcoholic patients with hepatic decompensation. ${ }^{85,86}$ Long-term nutritional supports are also beneficial in patients with alcoholic cirrhosis or chronic hepatic decompensation. ${ }^{87,88}$

A higher-than-usual dietary intake with protein amount of 1.2 to $1.5 \mathrm{~g} / \mathrm{kg}$ and kilocalorie intake of 35 to $40 \mathrm{kcal} / \mathrm{kg}$ is recommended. ${ }^{83}$ This recommendation by the American Association for the Study of Liver Diseases and the American College of Gastroenterology is based on a study in patients with cirrhosis, ${ }^{89}$ and such approaches were found to improve the efficiency of nitrogen metabolism and then reduce hospitalization as well as complications. ${ }^{27}$ It is also recommended that patients could have protein amount of $1.5 \mathrm{~g} / \mathrm{kg}$ and kilocalorie intake of $40 \mathrm{kcal} / \mathrm{kg}$ during acute illness or intermittent exacerbation of chronic disease. ${ }^{83}$ Branched-chain amino acids may be considered in patients who develop encephalopathy during protein feeding. ${ }^{87}$

Patients with decompensated cirrhosis should be referred for the possibility of liver transplantation. Transplantation for alcoholic liver disease provides survival benefit, better quality of life, and is thus cost-effective. ${ }^{90-92}$ Delayed referral for evaluation of transplantation leads to mortality during the waiting period. ${ }^{93}$ However, delayed referral may be due to active alcoholism. ${ }^{94}$ Psychosocial support and abstinence are important before transplantation. A 6-month period of abstinence has been widely used as a minimal listing criterion. ${ }^{91,95,96}$ Living donor liver transplantation (LDLT) in alcoholic liver disease has ethical issues on the indications and timing. ${ }^{97,98}$ LDLT should be considered only when there is a low risk of recidivism and a likelihood of good outcome.

The rate of recidivism after orthotopic liver transplantation (OLT) ranges from $7 \%$ to $31 \%$ in patients with alcoholic cirrhosis. ${ }^{99,100}$ A higher percentage of cirrhotic patients resuming alcohol use after transplantation has been reported, but only $5 \%$ to $7 \%$ have excessive drinking. ${ }^{100,101}$ The latter has similar overall compliance to immunosuppression and survival with transplant recipients for other diseases. Nevertheless, a study described the success of post-OLT alcoholism treatment programs to reduce the relapse rate of any drinking. ${ }^{102}$ Post-transplantation alcoholic liver disease patients in the United Kingdom have regular appointments with a psychiatrist in addictions treatment training. ${ }^{103,104}$

Alcoholic liver disease patients who receive liver transplantation have increased risk of lung, liver, and oropharyngeal cancer. ${ }^{105,106}$ It has been reported that up to $40 \%$ of post-transplant patients with alcoholic liver disease resume smoking. ${ }^{107}$ The high rate of post-transplant cancer may be due to prior smoking in combination with the impact of immunosuppression on tumor surveillance.

Two meta-analyses reported the benefit of corticosteroids in severe alcoholic hepatitis. ${ }^{108,109}$ A pooled analysis of data from randomized controlled trials also revealed their efficacy in improving short-term survival. ${ }^{110}$ However, the benefit of corticosteroids in severe alcoholic hepatitis superimposed on alcoholic cirrhosis remains unknown. Pentoxifylline of $400 \mathrm{mg} 3$ times daily for 6 months can reduce bacterial infection, renal failure, and hepatic encephalopathy in patients with advanced cirrhosis but not the short-term mortality. ${ }^{111}$

Potential hepatotoxic agents should be avoided in patients with cirrhosis, which include herbal remedies, acetaminophen, and drugs with hepatotoxic side effects. Hepatitis A and $\mathrm{B}$ vaccination should be considered to prevent additional insult to the liver with limited functional reserve. Pneumococcal and yearly influenza vaccination may also be beneficial. 


\section{Prevention and treatment of complications of alcoholic cirrhosis Ascites}

Nonsteroidal anti-inflammatory drugs may induce water retention and should be avoided. ${ }^{112}$ Dietary sodium restriction to $88 \mathrm{meq}(2000 \mathrm{mg})$ per day is recommended, which includes sodium in all foods, liquids, and medications. ${ }^{13,114}$ When liver function deteriorates, urinary sodium excretion declines. ${ }^{79}$ A combination of diuretics with sodium restriction is required. Successful treatment refers to reducing ascitic fluid volume without intravascular volume depletion. Treatment of ascites improves quality of life and protects against SBP.

\section{Varices and related hemorrhage}

Patients with alcoholic cirrhosis should undergo evaluation to assess the presence of varices and to determine the risk of variceal hemorrhage. ${ }^{43,50,52}$ To prevent varices and a first variceal bleeding, nonselective beta blockers are recommended for small varices which have a high risk of bleeding or varices in Child-Pugh B or C cirrhosis. Furthermore, nonselective beta blockers or endoscopic band ligation are suggested for medium or large varices. ${ }^{115}$ For treatment of acute variceal bleeding, combination of vasoconstrictor and endoscopic band ligation are recommended for Child-Pugh A or B patients or patients with an hepatic venous pressure gradient (HVPG) of less than $20 \mathrm{mmHg},{ }^{116,117}$ together with short-term prophylactic norfloxacin or ceftriaxone. ${ }^{118,119}$ In patients with Child-Pugh C or an HVPG of more than $20 \mathrm{mmHg}$, more aggressive treatment should be considered. Transjugular intrahepatic portosystemic shunt is a salvage therapy for patients who responded poorly to previous treatment, and early placement is suggested. Endoscopic variceal obturation with butyl cyanoacrylate is recommended for acute bleeding of gastric varices. ${ }^{120,121}$ To prevent recurrent variceal bleeding, a combination of endoscopic band ligation and nonselective beta-blockers is recommended. ${ }^{122}$

\section{Hepatic encephalopathy}

A precipitating factor can usually be identified when hepatic encephalopathy occurs. These factors include constipation, infection, gastrointestinal bleeding, increased protein intake, hypokalemic alkalosis, hypoxia, and sedatives. ${ }^{123}$ Treatment of these precipitating factors leads to a continuous and rapid improvement of encephalopathy. Nevertheless, protein restriction in acute encephalopathy is not recommended. ${ }^{24}$
Elevation of serum ammonia is detected in $60 \%$ to $80 \%$ of patients with hepatic encephalopathy. Lowering of the ammonia levels improves encephalopathy. Hypokalemia should be corrected because hypokalemia increases renal ammonia production. Lactulose is widely used to reduce ammonia and to inhibit its production. Although there is limited evidence from controlled trials, lactulose is the mainstay of treatment to improve encephalopathy, ${ }^{125}$ and to prevent its recurrence. ${ }^{126}$ Lactulose enemas have also been reported to be more effective than tap water enemas. ${ }^{127}$

Antibiotics can be also used to inhibit intestinal ammonia production and absorption. Rifaximin prevents recurrent hepatic encephalopathy over a 6-month period ${ }^{128}$ and is better tolerated than nonabsorbable disaccharides. ${ }^{129}$ Neomycin has been found to be similar in efficacy to lactulose, ${ }^{130}$ but also to placebo. ${ }^{131}$ However, the alteration in gut flora due to antibiotics use is a concern.

Intestinal ammonia production may also be inhibited by acarbose, an alpha glycosidase inhibitor. Acarbose has been shown in a randomized trial to reduce blood ammonia and improve encephalopathy in diabetes patients. ${ }^{132}$ Its efficacy and possible side effects in nondiabetic patients need further study.

Another approach to reduce ammonia is by stimulating glutamine synthesis which leads to enhancement of ammonia metabolism and removal. This can be achieved by ornithine and aspartate. Ornithine-aspartate has been described to be effective in mild hepatic encephalopathy, ${ }^{133,134}$ but not in acute liver failure. ${ }^{135}$

An increase in the plasma aromatic amino acids to branched-chain amino acids (BCAA) ratio has been proposed as another hypothesis of hepatic encephalopathy, besides the ammonia hypothesis. Parenteral BCAA supplementation has contradictory results in mortality. ${ }^{136,137}$ Several trials have found beneficial effects of oral BCAA in cirrhotic patients intolerant to protein or under a low protein diet. ${ }^{87,138}$

A third hypothesis of hepatic encephalopathy is the neuronal inhibition by GABA-receptor complex. This principal inhibitory network in the central nervous system includes the benzodiazepine receptor site. An increase in benzodiazepine receptor ligands has been proven in patients with hepatic encephalopathy. ${ }^{139}$ A meta-analysis showed that treatment with flumazenil, a benzodiazepine receptor antagonist, improves encephalopathy in some patients. ${ }^{140}$

Zinc and melatonin have been suggested in the treatment of hepatic encephalopathy. Cirrhotic patients with encephalopathy have zinc deficiency. ${ }^{141}$ Zinc supplement 
to improve encephalopathy has been described in case reports, ${ }^{142,143}$ but has not been proven in a double-blind trial. ${ }^{144}$ Cirrhotic patients have elevated daytime melatonin levels which may contribute to the disturbances of the sleep-wake cycle. ${ }^{145}$ Melatonin supplement may be an option to alter the sleep-wake cycle in these patients. ${ }^{146}$

\section{Spontaneous bacterial peritonitis}

Judicious use of diuresis can increase ascitic fluid opsonic activity and may prevent SBP. ${ }^{147}$ Aggressive treatment of infections at other sites can also prevent SBP. Antibiotics should be initiated early to maximize survival of the patients. ${ }^{114}$ Empirical antibiotics should be started when there is an unexplained presence of fever, abdominal pain or tenderness, altered mental status, or ascitic polymorphonuclear count of $\geq 250$ cells $/ \mathrm{mm}^{3}$. Most of the ascitic cultures in SBP reveal gut bacteria such as Escherichia coli and Klebsiella. A third-generation cephalosporin is a reasonable empirical antibiotic. ${ }^{57,148}$

A follow-up ascitic fluid after antibiotics treatment is not necessary in most patients with SBP who have dramatic clinical response. A 5-day treatment duration has been proven to be as effective as a 10 -day. ${ }^{149}$

\section{Hepatorenal syndrome}

The onset of renal impairment is insidious and may be precipated by gastrointestinal bleeding, infection, or overly rapid diuresis. The combination of a systemic vasoconstrictor (midodrine) and an inhibitor of endogenous vasodilator release (octreotide) but not octreotide alone improves renal and systemic hemodynamics. ${ }^{150,151}$ Vasopressin analogs plus plasma volume expansion may also be beneficial for hepatorenal syndrome. ${ }^{152-154}$

\section{Hepatopulmonary syndrome}

Currently, no medical therapy has been shown to significantly improve oxygenation. Liver transplantation is indicated for patients with severe and refractory hypoxemia.

\section{Hepatocellular carcinoma}

Surveillance for hepatocellular carcinoma in patients with alcoholic cirrhosis is recommended to allow earlier detection of hepatocellular carcinoma to achieve better treatment response.

\section{Disclosure}

The authors report no conflicts of interest in this work.

\section{References}

1. Becker U, Deis A, Sorensen TI, et al. Prediction of risk of liver disease by alcohol intake, sex, and age: a prospective population study. Hepatology. 1996;23:1025-1029.

2. Review by an international group. Alcoholic liver disease: morphological manifestations. Lancet. 1981;317:707-711.

3. Klatsky AL, Armstrong MA. Alcohol, smoking, coffee, and cirrhosis. Am J Epidemiol. 1992;136:1248-1257.

4. Zakim D, Boyer TD, Montgomery C. Alcoholic liver disease Hepatology: Textbook of Liver Disease. Philadelphia: Saunders; 1990:821.

5. Enomoto N, Takase S, Takada N, Takada A. Alcoholic liver disease in heterozygotes of mutant and normal aldehyde dehydrogenase-2 genes. Hepatology. 1991;13:1071-1075.

6. Shibuya A, Yoshida A. Genotypes of alcohol-metabolizing enzymes in Japanese with alcohol liver diseases: a strong association of the usual Caucasian-type aldehyde dehydrogenase gene $\left(\mathrm{ALDH}_{2}^{1}\right)$ with the disease. Am J Hum Genet. 1988;43:744-748.

7. Chao YC, Liou SR, Chung YY, et al. Polymorphism of alcohol and aldehyde dehydrogenase genes and alcoholic cirrhosis in Chinese patients. Hepatology. 1994;19:360-366.

8. Chao YC, Young TH, Tang HS, Hsu CT. Alcoholism and alcoholic organ damage and genetic polymorphisms of alcohol metabolizing enzymes in Chinese patients. Hepatology. 1997;25:112-117.

9. Nieto N, Friedman SL, Cederbaum AI. Cytochrome P450 2E1-derived reactive oxygen species mediate paracrine stimulation of collagen I protein synthesis by hepatic stellate cells. J Biol Chem. 2002;277: 9853-9864.

10. Castillo T, Koop DR, Kamimura S, Triadafilopoulos G, TsukamotoH. Role of cytochrome P-450 2E1 in ethanol-, carbon tetrachloride- and iron-dependent microsomal lipid peroxidation. Hepatology. 1992;16:992-996.

11. Parola M, Robino G. Oxidative stress-related molecules and liver fibrosis. J Hepatology. 2001;35:297-306.

12. Sastre J, Serviddio G, Pereda J, et al. Mitochondrial function in liver disease. Front Biosci. 2007;12:1200-1209.

13. Lieber CS. Alcoholic fatty liver: its pathogenesis and mechanism of progression to inflammation and fibrosis. Alcohol. 2004;34:9-19.

14. Yang SS, Huang CC, Chen JR, et al. Effects of ethanol on antioxidant capacity in isolated rat hepatocytes. World J Gastroenterol. 2005;11:7272-7276.

15. French SW, Nash J, Shitabata P, et al. Pathology of alcoholic liver disease. Semin Liver Dis. 1993;13:154-169.

16. Friedman SL. Mechanisms of hepatic fibrogenesis. Gastroenterology. 2008;134:1655-1669.

17. Tsukamoto H, Gaal K, French SW. Insights into the pathogenesis of alcoholic liver necrosis and fibrosis: status report. Hepatology. 1990;12:599-608.

18. Okanoue T, Burbige EJ, French SW. The role of the Ito cell in perivenular and intralobular fibrosis in alcoholic hepatitis. Arch Pathol Lab Med. 1983;107:459-463.

19. Paik YH, Schwabe RF, Bataller R, Russo MP, Jobin C, Brenner DA. Toll-like receptor 4 mediates inflammatory signaling by bacterial lipopolysaccharide in human hepatic stellate cells. Hepatology. 2003;37: 1043-1055.

20. Seki E, de Minicis S, Osterreicher CH, et al. TLR4 enhances TGF-beta signaling and hepatic fibrosis. Nat Med. 2007;13:1324-1332.

21. Casini A, Cunningham M, Rojkind M, Lieber CS. Acetaldehyde increases procollagen type I and fibronectin gene transcription in cultured rat fat-storing cells through a protein synthesis-dependent mechanism. Hepatology. 1991;13:758-765.

22. Kamimura S, Gaal K, Britton RS, Bacon BR, Triadafilopoulos G, Tsukamoto H. Increased 4-hydroxynonenal levels in experimental alcoholic liver disease: association of lipid peroxidation with liver fibrogenesis. Hepatology. 1992;16:448-453.

23. Kawase T, Kato S, Lieber CS. Lipid peroxidation and antioxidant defense systems in rat liver after chronic ethanol feeding. Hepatology. 1989;10:815-821. 
24. Sheron N, Bird G, Koskinas J, et al. Circulating and tissue levels of the neutrophil chemotaxin interleukin- 8 are elevated in severe acute alcoholic hepatitis, and tissue levels correlate with neutrophil infiltration. Hepatology. 1993;18:41-46.

25. McClain CS, Hill D, Schmidt J, Diehl AM. Cytokines and alcoholic liver disease. Semin Liver Dis. 1993;13:170-182.

26. Adachi M, Brenner DA. Clinical syndromes of alcoholic liver disease. Dig Dis. 2005;23:255-263.

27. McCullough AJ, O'Connor JF. Alcoholic liver disease: proposed recommendations for the American College of Gastroenterology. Am J Gastroenterol. 1998;93:2022-2036.

28. Yang SS. Alcoholic liver disease: clinical and sonographic features. J Med Ultrasound. 2008;16:140-149.

29. Okazaki H, Ito K, Fujita T, Koike S, Takano K, Matsunaga N. Discrimination of alcoholic from virus-induced cirrhosis on MR imaging. AJR Am J Roentgenol. 2000;175:1677-1681.

30. Menon DK, Sargentoni J, Taylor-Robinson SD, et al. Effect of functional grade and etiology on in vivo hepatic phosphorus-31 magnetic resonance spectroscopy in cirrhosis: biochemical basis of spectral appearances. Hepatology. 1995;21:417-427.

31. Schlemmer HP, Sawatzki T, Sammet S, et al. Hepatic phospholipids in alcoholic liver disease assessed by proton-decoupled ${ }^{31} \mathrm{P}$ magnetic resonance spectroscopy. J Hepatol. 2005;42:752-759.

32. Worner TM, Lieber CS. Perivenular fibrosis as precursor lesion of cirrhosis. JAMA. 1985;254:627-630.

33. Chedid A, Mendenhall CL, Tosch T, et al. Significance of megamitochondria in alcoholic liver disease. Gastroenterology. 1986;90: 1858-1864.

34. Talley NJ, Roth A, Woods J, Hench V. Diagnostic value of liver biopsy in alcoholic liver disease. J Clin Gastroenterol. 1988;10:647-650.

35. Nagula S, Jain D, Groszmann RJ, Garcia-Tsao G. Histologicalhemodynamic correlation in cirrhosis - a histological classification of the severity of cirrhosis. J Hepatol. 2006;44:111-117.

36. Issa R, Zhou X, Constandinou CM, et al. Spontaneous recovery from micronodular cirrhosis: evidence for incomplete resolution associated with matrix cross-linking. Gastroenterology. 2004;126: 1795-1808

37. Teli MR, Day CP, Burt AD, Bennett MK, James OF. Determinants of progression to cirrhosis or fibrosis in pure alcoholic fatty liver. Lancet. 1995;346:987-990.

38. Nakano M, Worner TM, Lieber CS. Perivenular fibrosis in alcoholic liver injury: ultrastructure and histologic progression. Gastroenterology. 1982;83:777-785.

39. Castera L, Vergniol J, Foucher J, et al. Prospective comparison of transient elastography, fibrotest, APRI, and liver biopsy for the assessment of fibrosis in chronic hepatitis C. Gastroenterology. 2005;128: $343-350$.

40. Arena U, Vizzutti F, Corti G, et al. Acute viral hepatitis increases liver stiffness values measured by transient elastography. Hepatology. 2008;47:380-384

41. Sagir A, Erhardt A, Schmitt M, Haussinger D. Transient elastography is unreliable for detection of cirrhosis in patients with acute liver damage. Hepatology. 2008;47:592-595.

42. Jepsen P, Ott P, Andersen PK, Sorensen HT, Vilstrup H. Clinical course of alcoholic liver cirrhosis: a Danish population-based cohort study. Hepatology. 2010;51:1675-1682.

43. Huang YW, Hu JT, Yang SS. Complications of alcoholic liver cirrhosis: active assessment by endoscopy and sonography. Hepatology. 2010;52:1864-1865.

44. Galambos JT. Alcoholic hepatitis: its therapy and prognosis. Prog Liver Dis. 1972;4:567-588.

45. Pares A, Caballeria J, Bruguera M, Torres M, Rodes J. Histological course of alcoholic hepatitis: influence of abstinence, sex and extent of hepatic damage. J Hepatol. 1986;2:33-42.

46. Morgan MY. The prognosis and outcome of alcoholic liver disease. Alcohol Alcohol Suppl. 1994;2:335-343.
47. Wensing G, Lotterer E, Link I, Hahn EG, Fleig WE. Urinary sodium balance in patients with cirrhosis: relationship to quantitative parameters of liver function. Hepatology. 1997;26:1149-1155.

48. Gines P, Quintero E, Arroyo V, et al. Compensated cirrhosis: natural history and prognostic factors. Hepatology. 1987;7:122-128.

49. Yang SS, Ralls PW, Korula J. The effect of oral nitroglycerin on portal blood velocity as measured by ultrasonic Doppler: a double blind, placebo controlled study. J Clin Gastroenterol. 1991;13:173-177.

50. D'Amico G, Garcia-Tsao G, Pagliaro L. Natural history and prognostic indicators of survival in cirrhosis: a systematic review of 118 studies. J Hepatol. 2006;44:217-231.

51. Yang SS, Hu JT, Huang YW, Hsu MY, Chang HY. The study of narrow band imaging system in the evaluation of esophageal varices. Gastroenterol J Taiwan. 2009;26:164-169.

52. Lin $\mathrm{CW}$, Chen YS, Lai $\mathrm{CH}$, et al. Esophagogastric varices predict mortality in hospitalized patients with alcoholic liver disease in Taiwan. Hepatogastroenterol. 2010;57:285-289.

53. Grace ND. Prevention of initial variceal hemorrhage. Gastroenterol Clin North Am. 1992;21:149-161.

54. Chu NS, Yang SS. Somatosensory and brainstem auditory evoked potentials in alcoholic liver disease with and without encephalopathy. Alcohol. 1987;4:225-230.

55. Yang SS, Chu NS, Wu CH. The role of somatosensory evoked potentials on hepatic encephalopathy. Biomed Eng Appl Basis Comm. 1997;9:154-157.

56. Wein C, Koch H, Popp B, Oehler G, Schauder P. Minimal hepatic encephalopathy impairs fitness to drive. Hepatology. 2004;39:739-745.

57. Such J, Runyon BA. Spontaneous bacterial peritonitis. Clin Infect Dis. 1998;27:669-674.

58. Gines P, Schrier RW. Renal failure in cirrhosis. $N$ Engl J Med. 2009;361:1279-1290.

59. Gines P, Guevara M, Arroyo V, Rodes J. Hepatorenal syndrome. Lancet. 2003;362:1819-1827.

60. Akriviadis E, Botla R, Briggs W, Han S, Reynolds T, Shakil O. Pentoxifylline improves short-term survival in severe acute alcoholic hepatitis: a double-blind, placebo-controlled trial. Gastroenterology. 2000;119:1637-1648.

61. Hoeper MM, Krowka MJ, Strassburg CP. Portopulmonary hypertension and hepatopulmonary syndrome. Lancet. 2004;363:1461-1468.

62. Rodriguez-Roisin R, Krowka MJ. Hepatopulmonary syndrome - a liver-induced lung vascular disorder. N Engl J Med. 2008;358: 2378-2387.

63. Stoller JK, Lange PA, Westveer MK, Carey WD, Vogt D, Henderson JM. Prevalence and reversibility of the hepatopulmonary syndrome after liver transplantation. The Cleveland Clinic experience. West J Med. 1995;163:133-138.

64. Hopkins WE, Waggoner AD, Barzilai B. Frequency and significance of intrapulmonary right-to-left shunting in end-stage hepatic disease. Am J Cardiol. 1992;70:516-519.

65. Naeije R, Melot C, Hallemans R, Mols P, Lejeune P. Pulmonary hemodynamics in liver cirrhosis. Semin Respir Med. 1985;7:164-170.

66. Lange PA, Stoller JK. The hepatopulmonary syndrome. Ann Intern Med. 1995;122:521-529.

67. Chen DS, Sung JL, Sheu JC, et al. Serum alpha-fetoprotein in the early stage of human hepatocellular carcinoma. Gastroenterology. 1984;86:1404-1409.

68. Fasani P, Sangiovanni A, de Fazio C, et al. High prevalence of multinodular hepatocellular carcinoma in patients with cirrhosis attributable to multiple risk factors. Hepatology. 1999;29:1704-1707.

69. Infante-Rivard C, Esnaola S, Villeneuve JP. Clinical and statistical validity of conventional prognostic factors in predicting short-term survival among cirrhotics. Hepatology. 1987;7:660-664.

70. Albers I, Hartmann H, Bircher J, Creutzfeldt W. Superiority of the Child-Pugh classification to quantitative liver function tests for assessing prognosis of liver cirrhosis. Scand J Gastroenterol. 1989;24: 269-276. 
71. Orrego H, Blake JR, Blendis LM, Medline A. Prognosis of alcoholic cirrhosis in the presence and absence of alcoholic hepatitis. Gastroenterology. 1987;92:208-214.

72. Mookerjee RP, Malaki M, Davies NA, et al. Increasing dimethylarginine levels are associated with adverse clinical outcome in severe alcoholic hepatitis. Hepatology. 2007;45:62-71.

73. Imperiale TF, McCullough AJ. Do corticosteroids reduce mortality from alcoholic hepatitis? A meta-analysis of the randomized trials. Ann Intern Med. 1990;113:299-307.

74. Maddrey WC, Boitnott JK, Bedine MS, Weber FL Jr, Mezey E, White RI Jr. Corticosteroid therapy of alcoholic hepatitis. Gastroenterology. 1978;75:193-199.

75. Forrest EH, Evans CD, Stewart S, et al. Analysis of factors predictive of mortality in alcoholic hepatitis and derivation and validation of the Glasgow alcoholic hepatitis score. Gut. 2005;54:1174-1179.

76. Louvet A, Naveau S, Abdelnour M, et al. The Lille model: a new tool for therapeutic strategy in patients with severe alcoholic hepatitis treated with steroids. Hepatology. 2007;45:1348-1354.

77. Naveau S, Cassard-Doulcier AM, Njike-Nakseu M, et al. Harmful effect of adipose tissue on liver lesions in patients with alcoholic liver disease. J Hepatol. 2010;52:895-902.

78. Reynolds TB, Geller HM, Kuzma OT, Redeker AG. Spontaneous decrease in portal pressure with clinical improvement in cirrhosis. N Engl J Med. 1960;263:734-739.

79. Runyon BA. Historical aspects of treatment of patients with cirrhosis and ascites. Semin Liver Dis. 1997;17:163-173.

80. Niemela O, Risteli J, Blake JE, Risteli L, Compton KV, Orrego H Markers of fibrogenesis and basement membrane formation in alcoholic liver disease. Relation to severity, presence of hepatitis, and alcohol intake. Gastroenterology. 1990;98:1612-1619.

81. Alexander JF, Lischner MW, Galambos JT. Natural history of alcoholic hepatitis. II. The long-term prognosis. Am J Gastroenterol. 1971;56:515-525.

82. Yang SS, Wu CH, Chen LL, Mo SC, Chen DF. Nutritional status in non-alcoholic sub-clinical porto-systemic encephalopathy. World $J$ Gastroenterol. 1998;4:380-384.

83. O'Shea RS, Dasarathy S, McCullough AJ. Alcoholic liver disease Hepatology. 2010;51:307-328.

84. Mendenhall CL, Anderson S, Weesner RE, Goldberg SJ, Crolic KA Protein-calorie malnutrition associated with alcoholic hepatitis. Veterans Administration Cooperative Study Group on Alcoholic Hepatitis. Am J Med. 1984;76:211-222.

85. Kearns PJ, Young H, Garcia G, et al. Accelerated improvement of alcoholic liver disease with enteral nutrition. Gastroenterology. 1992;102:200-205.

86. Cabre E, Gonzalez-Huix F, Abad-Lacruz A, et al. Effect of total enteral nutrition on the short-term outcome of severely malnourished cirrhotics. A randomized controlled trial. Gastroenterology. 1990;98: 715-720.

87. Marchesini G, Dioguardi FS, Bianchi GP, et al. Long-term oral branched-chain amino acid treatment in chronic hepatic encephalopathy. A randomized double-blind casein-controlled trial. The Italian Multicenter Study Group. J Hepatol. 1990;11:92-101.

88. Hirsch S, Bunout D, de la Maza P, et al. Controlled trial on nutrition supplementation in outpatients with symptomatic alcoholic cirrhosis. JPEN J Parenter Enteral Nutr. 1993;17:119-124.

89. Swart GR, Zillikens MC, van Vuure JK, van den Berg JW. Effect of a late evening meal on nitrogen balance in patients with cirrhosis of the liver. BMJ. 1989;299:1202-1203.

90. De Gottardi A, Dumortier J. Transplantation for alcoholic liver disease. Gut. 2007;56:735-736.

91. Kumar S, Stauber RE, Gavaler JS. Orthotopic liver transplantation for alcoholic liver disease. Hepatology. 1990;11:159-164.

92. Longworth L, Young T, Buxton MJ, et al. Midterm cost-effectiveness of the liver transplantation program of England and Wales for three disease groups. Liver Transpl. 2003;9:1295-1307.
93. Everhart JE, Lombardero M, Detre KM, et al. Increased waiting time for liver transplantation results in higher mortality. Transplantation. 1997;64:1300-1306.

94. Julapalli VR, Kramer JR, El-Serag HB. Evaluation for liver transplantation: adherence to AASLD referral guidelines in a large Veterans Affairs center. Liver Transpl. 2005;11:1370-1378.

95. Bird GL, O’Grady JG, Harvey FA, Calne RY, Williams R. Liver transplantation in patients with alcoholic cirrhosis: selection criteria and rates of survival and relapse. BMJ. 1990;301:15-17.

96. Osorio RW, Ascher NL, Avery M, Bacchetti P, Roberts JP, Lake JR. Predicting recidivism after orthotopic liver transplantation for alcoholic liver disease. Hepatology. 1994;20:105-110.

97. Bramstedt KA, Jabbour N. When alcohol abstinence criteria create ethical dilemmas for the liver transplant team. JMed Ethics. 2006;32: 263-265.

98. Schiano TD, Kim-Schluger L, Gondolesi G, Miller CM. Adult living donor liver transplantation: the hepatologist's perspective. Hepatology. 2001;33:3-9.

99. Berlakovich GA, Steininger R, Herbst F, Barlan M, Mittlbock M, Muhlbacher F. Efficacy of liver transplantation for alcoholic cirrhosis with respect to recidivism and compliance. Transplantation. 1994;58:560-565.

100. Fabrega E, Crespo J, Casafont F, de las Heras G, de la Pena J, Pons-Romero F. Alcoholic recidivism after liver transplantation for alcoholic cirrhosis. J Clin Gastroenterol. 1998;26:204-206.

101. Gerhardt TC, Goldstein RM, Urschel HC, et al. Alcohol use following liver transplantation for alcoholic cirrhosis. Transplantation. 1996;62:1060-1063.

102. Bjornsson E, Olsson J, Rydell A, et al. Long-term follow-up of patients with alcoholic liver disease after liver transplantation in Sweden: impact of structured management on recidivism. Scand J Gastroenterol. 2005;40:206-216.

103. Kotlyar DS, Burke A, Campbell MS, Weinrieb RM. A critical review of candidacy for orthotopic liver transplantation in alcoholic liver disease. Am J Gastroenterol. 2008;103:734-743.

104. Bathgate AJ. Recommendations for alcoholic liver disease. Lancet. 2006;367:2045-2046.

105. Jain A, DiMartini A, Kashyap R, Youk A, Rohal S, Fung J. Long-term follow-up after liver transplantation for alcoholic liver disease under tacrolimus. Transplantation. 2000;70:1335-1342.

106. Boffetta P, Hashibe M. Alcohol and cancer. Lancet Oncol. 2006; 7:149-156.

107. Dimartini A, Javed L, Russell S, et al. Tobacco use following liver transplantation for alcoholic liver disease: an underestimated problem. Liver Transpl. 2005;11:679-683.

108. Imperiale TF, McCullough AJ. Do corticosteroids reduce mortality from alcoholic hepatitis? A meta-analysis of the randomized trials. Ann Intern Med. 1990;113:299-307.

109. Reynolds TB, Benhamou JP, Blake J, et al. Treatment of acute alcoholic hepatitis. Gastroenterol Int. 1989;2:308.

110. Mathurin P, Mendenhall CL, Carithers RL Jr, et al. Corticosteroids improve short-term survival in patients with severe alcoholic hepatitis $(\mathrm{AH})$ : individual data analysis of the last three randomized placebo controlled double blind trials of corticosteroids in severe $\mathrm{AH}$. J Hepatol. 2002;36:480-487.

111. Lebrec D, Thabut D, Oberti F, et al. Pentoxifylline does not decrease short-term mortality but does reduce complications in patients with advanced cirrhosis. Gastroenterology. 2010;138:1755-1762.

112. Arroyo V, Ginés P, Rimola A, Gaya L. Renal function abnormalities, prostaglandins, and effects of nonsteroidal anti-inflammatory drugs in cirrhosis with ascites. An overview with emphasis on pathogenesis. Am J Med. 1986;81:104-122.

113. Runyon BA, Montano AA, Akriviadis EA, Antillon MR, Irving MA, McHutchison JG. The serum-ascites albumin gradient is superior to the exudates-transudate concept in the differential diagnosis of ascites. Ann Intern Med. 1992;117:215-220. 
114. Runyon BA. Management of adult patients with ascites due to cirrhosis: an update. Hepatology. 2009;49:2087-2107.

115. Gluud LL, Klingenberg S, Nikolova D, Gluud C. Banding ligation versus beta-blockers as primary prophylaxis in esophageal varices: systemic review of randomized trials. Am J Gastroenterol. 2007; 102:2842-2848.

116. Villanueva C, Piqueras M, Aracil C, et al. A randomized controlled trial comparing ligation and sclerotherapy as emergency endoscopic treatment added to somatostatin in acute variceal bleeding. J Hepatol. 2006;45:560-567.

117. Banares R, Albillos A, Rincon D, et al. Endoscopic treatment versus endoscopic plus pharmacologic treatment for acute variceal bleeding: a meta-analysis. Hepatology. 2002;35:609-615.

118. Bernard B, Grange JD, Khac EN, Amiot X, Opolon P, Poynard T. Antibiotic prophylaxis for the prevention of bacterial infections in cirrhotic patients with gastrointestinal bleeding: a meta-analysis. Hepatology. 1999;29:1655-1661.

119. Fernandez J, Ruiz del Arbol L, Gomez C, et al. Norfloxacin vs ceftriaxone in the prophylaxis of infections in patients with advanced cirrhosis and hemorrhage. Gastroenterology. 2006;131:1049-1056.

120. Lo GH, Lai KH, Cheng JS, Chen MH, Chiang HT. A prospective, randomized trial of butyl cyanoacrylate injection versus band ligation in the management of bleeding gastric varices. Hepatology. 2001;33:1060-1064.

121. Tan PC, Hou MC, Lin HC, et al. A randomized trial of endoscopic treatment of acute gastric variceal hemorrhage: N-butyl-2-cyanoacrylate injection versus band ligation. Hepatology. 2006;43:690-697. [Erratum, Hepatology. 2006;43:1410.]

122. Gonzalez R, Zamora J, Gomez-Camarero J, Molinero LM, Banares R, Albillos A. Combination endoscopic and drug therapy to prevent variceal rebleeding in cirrhosis. Ann Intern Med. 2008;149:109-122.

123. Conn HO. A rational program for the management of hepatic coma. Gastroenterology. 1969;57:715-723.

124. Cordoba J, Lopez-Hellin J, Planas M, et al. Normal protein diet for episodic hepatic encephalopathy: results of a randomized study. J Hepatol. 2004;41:38-43.

125. Prasad S, Dhiman RK, Duseja A, Chawla YK, Sharma A, Agarwal R. Lactulose improves cognitive functions and health-related quality of life in patients with cirrhosis who have minimal hepatic encephalopathy. Hepatology. 2007;45:549-559.

126. Sharma BC, Sharma P, Agrawal A, Sarin SK. Secondary prophylaxis of hepatic encephalopathy: an open-label randomized controlled trial of lactulose versus placebo. Gastroenterology. 2009;137: 885-891.

127. Uribe M, Campollo O, Vargas F, et al. Acidifying enemas (lactitol and lactose) vs nonacidifying enemas (tap water) to treat acute portalsystemic encephalopathy: a double-blind, randomized clinical trial. Hepatology. 1987;7:639-643.

128. Bass NM, Mullen KD, Sanyal A, et al. Rifaximin treatment in hepatic encephalopathy. N Engl J Med. 2010;362:1071-1081.

129. Jiang Q, Jiang XH, Zheng MH, Jiang LM, Chen YP, Wang L. Rifaximin versus nonabsorbable disaccharides in the management of hepatic encephalopathy: a meta-analysis. Eur J Gastroenterol Hepatol. 2008;20:1064-1070.

130. Conn HO, Leevy CM, Vlahcevic ZR, et al. Comparison of lactulose and neomycin in the treatment of chronic portal-systemic encephalopathy. A double blind controlled trial. Gastroenterology. 1977;72:573-583.

131. Strauss E, Tramote R, Silva EP, et al. Double-blind randomized clinical trial comparing neomycin and placebo in the treatment of exogenous hepatic encephalopathy. Hepatogastroenterology. 1992;39: $542-545$.

132. Gentile S, Guarino G, Romano M, et al. A randomized controlled trial of acarbose in hepatic encephalopathy. Clin Gastroenterol Hepatol. 2005;3:184-191.
133. Stauch S, Kircheis G, Adler G, et al. Oral L-ornithine-L-aspartate therapy of chronic hepatic encephalopathy: results of a placebocontrolled double-blind study. J Hepatol. 1998;28:856-864.

134. Kircheis G, Nilius R, Held C, et al. Therapeutic efficacy of L-ornithine-L-aspartate infusions in patients with cirrhosis and hepatic encephalopathy: results of a placebo-controlled, double-blind study. Hepatology. 1997;25:1351-1360.

135. Acharya SK, Bhatia V, Sreenivas V, Khanal S, Panda SK. Efficacy of L-ornithine L-aspartate in acute liver failure: a doubleblind, randomized, placebo-controlled study. Gastroenterology. 2009;136:2159-2168.

136. Ferenci P. Critical evaluation of the role of branched chain amino acids in liver disease. In: Thomas JC, Jones EA, editors. Recent Advances in Hepatology. New York: Churchill Livingstone; 1986:137.

137. Naylor CD, O'Rourke K, Detsky AS, Baker JP. Parenteral nutrition with branched-chain amino acids in hepatic encephalopathy. A metaanalysis. Gastroenterology. 1989;97:1033-1042.

138. Horst D, Grace ND, Conn HO, et al. Comparison of dietary protein with an oral, branched chain-enriched amino acid supplement in chronic portal-systemic encephalopathy: a randomized controlled trial. Hepatology. 1984;4:279-287.

139. Basile AS, Hughes RD, Harrison PM, et al. Elevated brain concentrations of 1,4-benzodiazepines in fulminant hepatic failure. $N$ Engl $J$ Med. 1991;325:473-478.

140. Goulenok C, Bernard B, Cadranel JF, et al. Flumazenil vs. placebo in hepatic encephalopathy in patients with cirrhosis: a meta-analysis. Aliment Pharmacol Ther. 2002;16:361-372.

141. Loomba V, Pawar G, Dhar KL, Setia MS. Serum zinc levels in hepatic encephalopathy. Indian J Gastroenterol. 1995;14:51-53.

142. Marchesini G, Fabbri A, Bianchi G, Brizi M, Zoli M. Zinc supplementation and amino acid-nitrogen metabolism in patients with advanced cirrhosis. Hepatology. 1996;23:1084-1092.

143. Van der Rijt CC, Schalm SW, Schat H, Foeken K, de Jong G. Overt hepatic encephalopathy precipitated by zinc deficiency. Gastroenterology. 1991;100:1114-1118.

144. Riggio O, Ariosto F, Merli M, et al. Short-term oral zinc supplementation does not improve chronic hepatic encephalopathy. Results of a double-blind crossover trial. Dig Dis Sci. 1991;36:1204-1208.

145. Steindl PE, Finn B, Bendok B, Rothke S, Zee PC, Blei AT. Disruption of the diurnal rhythm of plasma melatonin in cirrhosis. Ann Intern Med. 1995;123:274-277.

146. Lewy AJ, Ahmed S, Jackson JM, Sack RL. Melatonin shifts human circadian rhythms according to a phase-response curve. Chronobiol Int. 1992;9:380-392.

147. Runyon BA, Antillon MR, Montano AA. Effect of dieresis versus therapeutic paracentesis on ascitic fluid opsonic activity and serum complement. Gastroenterology. 1989;97:158-162.

148. Felisart J, Rimola A, Arroyo V, et al. Cefotaxime is more effective than is ampicillin-tobramycin in cirrhotics with severe infections. Hepatology. 1985;5:457-462.

149. Runyon BA, McHutchison JG, Antillon MR, Akriviadis EA, Montano AA. Short-course versus long-course antibiotic treatment of spontaneous bacterial peritonitis. A randomized controlled study of 100 patients. Gastroenterology. 1991;100:1737-1742.

150. Kalambokis G, Economou M, Fotopoulos A, et al. The effects of chronic treatment with octreotide versus octreotide plus Midodrine on systemic hemodynamics and renal hemodynamics and function in nonazotemic cirrhotic patients with ascites. Am J Gastroenterol. 2005;100:879-885.

151. Pomier-Layrargues G, Paquin SC, Hassoun Z, Lafortune M, Tran A. Octreotide in hepatorenal syndrome: a randomized, doubleblind, placebo-controlled, crossover study. Hepatology. 2003;38: 238-243.

152. Guevara M, Gines P, Fernandez-Esparrach G, et al. Reversibility of hepatorenal syndrome by prolonged administration of ornipressin and plasma volume expansion. Hepatology. 1998;27:35-41. 
153. Martin-Llahi M, Pepin MN, Guevara M, et al. Terlipressin and albumin vs albumin in patients with cirrhosis and hepatorenal syndrome: a randomized study. Gastroenterology. 2008;134:1352-1359.
154. Sanyal AJ, Boyer T, Garcia-Tsao G, et al. A randomized, prospective, double-blind, placebo-controlled trial of terlipressin for type 1 hepatorenal syndrome. Gastroenterology. 2008;134:1360-1368.

\section{Publish your work in this journal}

Hepatic Medicine: Evidence and Research is an international, peerreviewed, open access journal covering all aspects of adult and pediatric hepatology in the clinic and laboratory including the following topics: Pathology, pathophysiology of hepatic disease; Investigation and treatment of hepatic disease; Pharmacology of drugs used for the treatment of hepatic disease. Issues of patient safety and quality of care will also be considered. The manuscript management system is completely online and includes a very quick and fair peer-review system, which is all easy to use. Visit http://www.dovepress.com/ testimonials.php to read real quotes from published authors.

Submit your manuscript here: http://www.dovepress.com/hepatic-medicine-evidence-and-research-journal 